\title{
Task-sharing to support paediatric and child health service delivery in low- and middle-income countries: current practice and a scoping review of emerging opportunities
}

Yingxi Zhao ${ }^{1^{*}} \mathbb{D}$, Christiane Hagel $^{1}$, Raymond Tweheyo ${ }^{2,3}$, Nathanael Sirili ${ }^{4}$, David Gathara ${ }^{5,6}$ and Mike English ${ }^{1,5}$

\begin{abstract}
Background: Demographic and epidemiological changes have prompted thinking on the need to broaden the child health agenda to include care for complex and chronic conditions in the 0-19 years (paediatric) age range. Providing such services will be undermined by general and skilled paediatric workforce shortages especially in lowand middle-income countries (LMICS). In this paper, we aim to understand existing, sanctioned forms of task-sharing to support the delivery of care for more complex and chronic paediatric and child health conditions in LMICs and emerging opportunities for task-sharing. We specifically focus on conditions other than acute infectious diseases and malnutrition that are historically shifted.
\end{abstract}

Methods: We (1) reviewed the Global Burden of Diseases study to understand which conditions may need to be prioritized; (2) investigated training opportunities and national policies related to task-sharing (current practice) in five purposefully selected African countries (Kenya, Uganda, Tanzania, Malawi and South Africa); and (3) summarized reported experience of task-sharing and paediatric and child health service delivery through a scoping review of research literature in LMICs published between 1990 and 2019 using MEDLINE, Embase, Global Health, PsycINFO, CINAHL and the Cochrane Library.

Results: We found that while some training opportunities nominally support emerging roles for non-physician clinicians and nurses, formal scopes of practices often remain rather restricted and neither training nor policy seems well aligned with probable needs from high-burden complex and chronic conditions. From 83 studies in 24 LMICs, and aside from the historically shifted conditions, we found some evidence examining task-sharing for a small set of specific conditions (circumcision, some complex surgery, rheumatic heart diseases, epilepsy, mental health).

Conclusion: As child health strategies are further redesigned to address the previously unmet needs careful strategic thinking on the development of an appropriate paediatric workforce is needed. To achieve coverage at scale countries may need to transform their paediatric workforce including possible new roles for non-physician cadres to support safe, accessible and high-quality care.

Keywords: Paediatrics, Human resources for health, Task-shifting, Task-sharing, Clinical officer, Non-physician clinician, Clinician associate

\footnotetext{
*Correspondence: yingxi.zhao@ndm.ox.ac.uk

${ }^{1}$ Oxford Centre for Global Health Research, Nuffield Department of Medicine, University of Oxford, S Parks Rd, Oxford OX1 3SY, UK

Full list of author information is available at the end of the article
} permits use, sharing, adaptation, distribution and reproduction in any medium or format, as long as you give appropriate credit to the original author(s) and the source, provide a link to the Creative Commons licence, and indicate if changes were made. The images or other third party material in this article are included in the article's Creative Commons licence, unless indicated otherwise in a credit line to the material. If material is not included in the article's Creative Commons licence and your intended use is not permitted by statutory regulation or exceeds the permitted use, you will need to obtain permission directly from the copyright holder. To view a copy of this licence, visit http://creativecommons.org/licenses/by/4.0/. The Creative Commons Public Domain Dedication waiver (http://creativeco mmons.org/publicdomain/zero/1.0/) applies to the data made available in this article, unless otherwise stated in a credit line to the data. 


\section{Background}

Global strategies and initiatives for reducing child mortality and morbidity have previously focused on immunization, acute infectious diseases, and nutrition as part of the Integrated Management of Childhood Illness (IMCI) and transmission of HIV/AIDS [1, 2]. The transition to the Sustainable Development Goals (SGDs) prompted the global community to look forwards to broaden the agenda as part of "child health redesign" [3]. This includes care for complex and chronic conditions in the $0-19$ years age range (referred to in this paper as paediatric and child health care) that were previously neglected and that most health systems in low- and middle-income countries (LMICs) may not be well-designed to address $[3,4]$.

Expanding services to encompass complex and chronic conditions is threatened by workforce shortages. The World Health Organization (WHO) estimates a gap in the supply of 18 million health workers by 2030 mostly in LMICs [5] where there is likely to be a specific challenge with the skilled paediatric workforce. Paediatrician density in 2016 was 0.5 and 6 per 100,000 children in lowincome countries and lower-middle-income countries, respectively, as compared with a global mean of 32 [6]. Paediatricians also tend to work in tertiary hospitals or in the private sector, leaving few supporting primary or district-level public sector care [7]. Specialist paediatric nurses or non-physician clinicians are also scarce, and in the case of nurses legal restrictions may prevent their initiating or prescribing many forms of treatment. In most sub-Saharan African countries, general non-physician clinicians and nurses fill the gaps and deliver over $80 \%$ of primary care [6]. This leads to either de facto task-shifting or a lack of paediatric and child health care.

Task-shifting refers to "the rational redistribution of tasks among health workforce teams. Specific tasks are moved, where appropriate, from highly qualified health workers to health workers with shorter training and fewer qualifications in order to make more efficient use of the available human resources for health" [8]. Task-sharing, in comparison, emphasizes a team-based approach where different professionals work together to deliver services [9]. Task-shifting and sharing (hereinafter referred to as "task-sharing") have a long history [10]. For child health it is implicit in IMCI strategies [11]. More recently it is embedded in care for non-communicable diseases [12], mental health [13] and children and adolescents with HIV/AIDS [14]. Informal (or unsupervised) task-sharing often occurs in rural and remote areas where mid-level clinicians and nurses perform procedures outside of their official (and sometimes legal) scopes of practice $[15,16]$.

In this paper, we aimed to understand existing, sanctioned forms of task-sharing and explore emerging opportunities for task-sharing to support the delivery of care for complex and chronic paediatric and child health conditions in LMICs. We conducted three parallel activities: (1) we explored which conditions have the highest disease burden for those aged 0-19 years using patterns in middle and high-income countries to indicate likely future scenarios in LMICs; (2) we investigated the training opportunities and existing policy related to task-sharing that might support expanded paediatric and child health services in five purposefully selected African countries; and (3) we conducted a scoping review of research examining task-sharing for child and adolescent health in LMICs with a specific focus on conditions other than acute infectious diseases and malnutrition that are historically shifted. Finally, we triangulated and synthesized findings to summarize the opportunities, evidence, gaps and implications for paediatric and child health service delivery in LMICs.

\section{Methods \\ Understanding burden of diseases using the Global Burden of Disease 2019}

To understand what conditions in the $0-19$ years age range might need to be prioritized in LMICs we extracted disability-adjusted life-years (DALYs) of level 3 causes (diseases and injuries) for the age group " $<20$ years" in 2019 from the Global Burden of Disease study [17]. We did this for countries defined by the World Bank as: highincome, upper-middle-income, lower-middle-income, and low-income; using the patterns in the first two as an indication of likely future disease patterns in low-income and lower-middle-income countries that will occur with development. For each category of income-level, we selected the top 20 causes ranked by DALYs, and highlighted those likely to require greater emphasis in developing accessible high-quality paediatric services.

\section{Policy and document review of training opportunities and scope of practice}

Second, we examined national training policies and professional scopes of practice in five East and Southern African countries (Kenya, Uganda, Tanzania, Malawi and South Africa). All have large gaps in the availability of skilled health professionals [18] and were the common location of research in our scoping review. We characterized the different professionals offering care, the extent of their pre-service paediatric and child health training and opportunities for post-basic training in this field. We focused on physicians, nurses and non-physician clinicians (clinical officers, clinical associates, etc.) as the cadres of interest. We searched for documents or information (e.g. from websites) from approved training institutions, relevant regulatory councils and commissions. 
We reviewed schemes of service, relevant acts, tasksharing policies, other broad and disease-specific national strategic plans/policies to capture their scopes of practice.

\section{Scoping review of research literature on task-sharing and paediatric and child health service delivery}

Lastly, we conducted a scoping review [19] of studies examining the design and practice of task-sharing for paediatric and child health services in all LMICs (Additional file 1: Scoping review protocol and PRISMA diagram). In summary, we conducted a systematic search using MEDLINE, Embase, Global Health, PsycINFO, CINAHL and the Cochrane Library to identify relevant articles. We combined terms and phrases related to paediatrics, task-sharing, different cadres commonly involved in task-sharing and the Cochrane LMIC filter [20]. We included all study designs published between 1990 and 2019 in English. Table 1 shows the inclusion and exclusion criteria. After two stages of independent screening by two authors, we charted data from included papers and sorted them into three major groups based on the conditions they examined: acute infectious diseases and malnutrition; surgery (with sub-categories minor surgery, other complex surgery), emergency and intensive care; and chronic conditions (sub-categories complex and chronic conditions, mental health). For included papers we described specific health services and procedures shifted/shared, study country, study design, cadres involved, major inputs and outcomes (health worker knowledge, skill, patient outcome) as originally reported in the included papers.

\section{Results}

\section{Burden of disease}

Focusing on those conditions not typically covered by current strategies and initiatives, Table 2 illustrates how the top-ranking conditions for which services will likely need strengthening will change as countries transition from low income to middle and high income if highquality paediatric care is to be widely accessible. For all countries, neonatal disorders (preterm, birth asphyxia and trauma, neonatal sepsis, etc.) are the highest-ranked cause. Malaria, lower respiratory infections and diarrheal diseases are the 2nd and 3rd top-ranked causes for lowincome and lower-middle-income countries, respectively, but covered by existing task-sharing strategies. Congenital birth defects are ranked 4th and 5th for low-income and lower-middle-income countries, respectively. Lower ranked but likely causes of substantial mortality and morbidity are road injuries, drowning, conflict and terrorism that require emergency and surgical care; and

Table 1 Inclusion and exclusion criteria for the scoping review of research evidence on task-sharing and paediatric and child health service delivery

\begin{tabular}{|c|c|}
\hline Include & Exclude \\
\hline \multicolumn{2}{|l|}{ Study objective } \\
\hline $\begin{array}{l}\text { - Evaluate task-sharing interventions } \\
\text { - Report task-sharing as norm (service normally delivered by non-physician } \\
\text { cadres) }\end{array}$ & $\begin{array}{l}\text { - Use non-physician cadres but do not aim to integrate task-sharing as } \\
\text { part of future routine care (e.g. training clinical officers to screen hearing } \\
\text { impairment to estimate its prevalence) }\end{array}$ \\
\hline \multicolumn{2}{|l|}{ Cadre } \\
\hline $\begin{array}{l}\text { - Clinical officer } \\
\text { - Other non-physician clinician } \\
\text { - Nurse } \\
\text { - Midwife } \\
\text { - Medical assistant }\end{array}$ & $\begin{array}{l}\text { - Community health worker/volunteer } \\
\text { - Lay health worker } \\
\text { - Health care support staff (without professional regulation) } \\
\text { - Patient or family }\end{array}$ \\
\hline \multicolumn{2}{|l|}{ Study setting } \\
\hline $\begin{array}{l}\text { - Hospital } \\
\text { - Clinics } \\
\text { - Community only if professional involved (community nurses) } \\
\text { In low- and middle-income countries }\end{array}$ & $\begin{array}{l}\text { - Community if managed by lay health worker/community health worker } \\
\text { - In high-income countries }\end{array}$ \\
\hline \multicolumn{2}{|l|}{ Service population } \\
\hline $\begin{array}{l}\text { - Children and adolescent } \\
\text { - Mixed population but state include children }\end{array}$ & $\begin{array}{l}\text { - Adult } \\
\text { - No detailed information on population }\end{array}$ \\
\hline \multicolumn{2}{|l|}{ Disease and service } \\
\hline - Any paediatrics preventive or curative service & $\begin{array}{l}\text { - Prevention of mother-to-child transmission (PMTCT) } \\
\text { - Emergency obstetric and newborn care } \\
\text { - Antenatal and postnatal care } \\
\text { - Family planning } \\
\text { - Dental service }\end{array}$ \\
\hline
\end{tabular}


Table 2 Top 20 conditions for population under 20 years ranked by DALYs in World Bank low-income, lower-middle-income, uppermiddle-income and high-income countries

\begin{tabular}{|c|c|c|c|c|}
\hline Rank & World Bank Low Income & World Bank Lower Middle Income & World Bank Upper Middle Income & World Bank High Income \\
\hline 1 & Neonatal disorders (11610.0) & Neonatal disorders (8890.5) & Neonatal disorders (2607.9) & Neonatal disorders (1041.5) \\
\hline 2 & Malaria (5302.7) & Lower respiratory infections (3121.7) & Congenital birth defects (1415.5) & Congenital birth defects (694.1) \\
\hline 3 & Lower respiratory infections (5251.6) & Diarrheal diseases (2546.6) & Lower respiratory infections (597.5) & Headache disorders (335.4) \\
\hline 4 & Diarrheal diseases (5004.1) & Congenital birth defects (1910.7) & Road injuries (513.5) & Anxiety disorders (319.9) \\
\hline 5 & Congenital birth defects (3284.5) & Malaria (1338.8) & Diarrheal diseases (309.0) & Asthma (317.1) \\
\hline 6 & Protein-energy malnutrition (1490.0) & Dietary iron deficiency (857.2) & Headache disorders (297.5) & Road injuries (305.6) \\
\hline 8 & Measles (1181.6) & Typhoid and paratyphoid (533.2) & Drowning (291.9) & Low back pain (295.5) \\
\hline 9 & HIV/AIDS (1095.2) & Road injuries (484.0) & Anxiety disorders (281.2) & Dermatitis (295.0) \\
\hline 10 & Whooping cough (1065.2) & Whooping cough (449.7) & Low back pain (197.2) & Conduct disorder (206.4) \\
\hline 11 & $\begin{array}{l}\text { Sexually transmitted infections } \\
\text { excluding HIV (877.5) }\end{array}$ & Protein-energy malnutrition (380.1) & Asthma (186.4) & Viral skin diseases (163.8) \\
\hline 12 & Dietary iron deficiency (876.6) & Tuberculosis (329.0) & HIV/AIDS (181.3) & $\begin{array}{l}\text { Endocrine, metabolic, blood, and } \\
\text { immune disorders (161.9) }\end{array}$ \\
\hline 13 & Tuberculosis (821.1) & $\begin{array}{l}\text { Hemoglobinopathies and hemolytic } \\
\text { anemias (320.4) }\end{array}$ & Conduct disorder (179.8) & Acne vulgaris (156.2) \\
\hline 14 & Road injuries (785.8) & Headache disorders (315.1) & Foreign body (175.6) & Drug use disorders (143.2) \\
\hline 15 & $\begin{array}{l}\text { Invasive Non-typhoidal Salmonella } \\
\text { (iNTS) (518.2) }\end{array}$ & Drowning (301.8) & Dietary iron deficiency (163.6) & Other musculoskeletal disorders (142.9) \\
\hline 16 & $\begin{array}{l}\text { Hemoglobinopathies and hemolytic } \\
\text { anemias (514.1) }\end{array}$ & $\begin{array}{l}\text { Invasive Non-typhoidal Salmonella } \\
\text { (iNTS) (278.4) }\end{array}$ & Leukaemia (161.5) & Self-harm (141.3) \\
\hline 17 & Conflict and terrorism (332.1) & $\begin{array}{l}\text { Sexually transmitted infections } \\
\text { excluding HIV (273.9) }\end{array}$ & Depressive disorders (160.7) & Falls (131.6) \\
\hline 18 & Drowning (315.8) & HIV/AIDS (264.0) & Dermatitis (149.8) & Interpersonal violence (125.0) \\
\hline 19 & Asthma (283.9) & Idiopathic epilepsy (201.0) & Idiopathic epilepsy (146.6) & Upper respiratory infections (124.8) \\
\hline 20 & Idiopathic epilepsy (257.7) & Conduct disorder (191.9) & $\begin{array}{l}\text { Endocrine, metabolic, blood, and } \\
\text { immune disorders (146.4) }\end{array}$ & Idiopathic epilepsy (111.1) \\
\hline
\end{tabular}

Conditions marked in grey are not traditionally covered by acute infectious diseases and malnutrition care

haemoglobinopathies and haemolytic anaemias, asthma, epilepsy and conduct disorder that are considered chronic conditions and require long-term multiple interactions with health services. Most of these conditions are also top-ranking conditions for upper-middle-income countries and high-income countries, which suggests that they will become increasingly important needs as countries develop economically.

\section{Training opportunities and scope of practice}

Table 3 summarizes the training opportunities and scope of practice related to child health for physicians, nonphysician clinicians and nurses/specialist nurses in the five African countries examined. The full list (by country and by cadre) is available in the Additional File 2. This details specific opportunities for child health training, existing child health scopes of practice (where defined) and summaries of national policies and planning documents relevant to child health.

In the countries examined physician training generally lasts $5-6$ years and is followed by a $1-2$ years pre-licensure internship that includes some months of supervised paediatric work within a hospital. All these countries offer physicians further specialist training in paediatrics and child health and family medicine, however graduates of these specialist medical programmes are few (e.g. $20-25$ pa in Kenya). It is implicit in most policies that non-specialist physicians, even if junior, are expected to provide care for chronic and complex paediatric conditions with the exception of major surgery or intensive care. As such they may be expected to supervise, teach or receive referrals from non-physician clinicians and nurses offering primary care paediatric services in the absence of specialist paediatricians.

For non-physician clinicians, most countries have 3-4-year entry-level diplomas or Bachelor's degrees that include some elements of paediatrics and child health (mostly 3-4 short courses). These diplomas and Bachelor's degrees also require several months of internship in paediatric wards pre-licensure with a relevant regulator. The scope of practice for non-physician clinicians usually includes prescription of common medication. In schemes of service documents some countries (Kenya, Tanzania, South Africa) also explicitly permit non-physician clinicians to perform certain typically minor surgical procedures. Three countries (Kenya, Uganda, Malawi) have advanced-level courses on paediatrics for non-physician clinicians while all countries have advanced diplomas in 


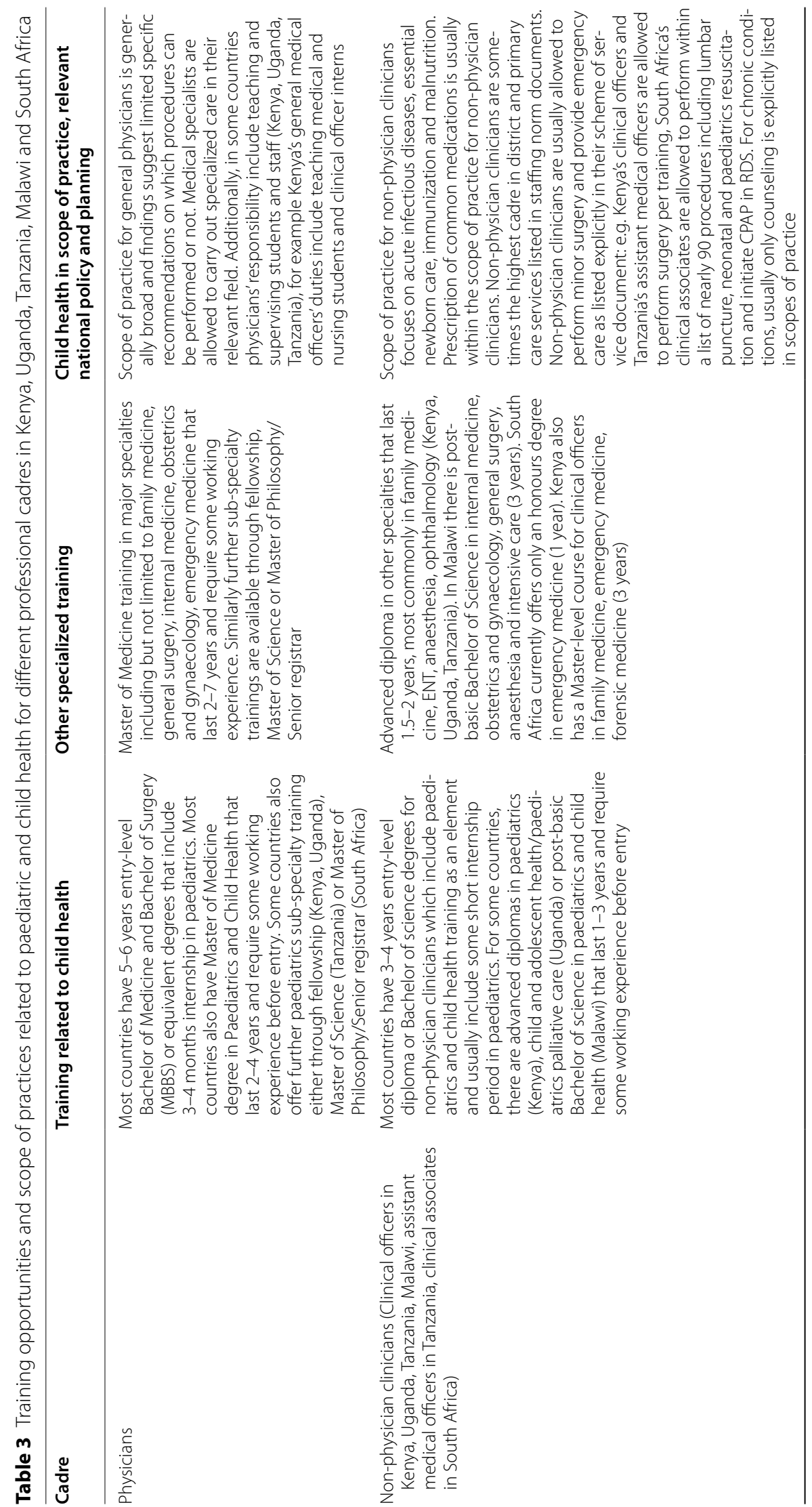




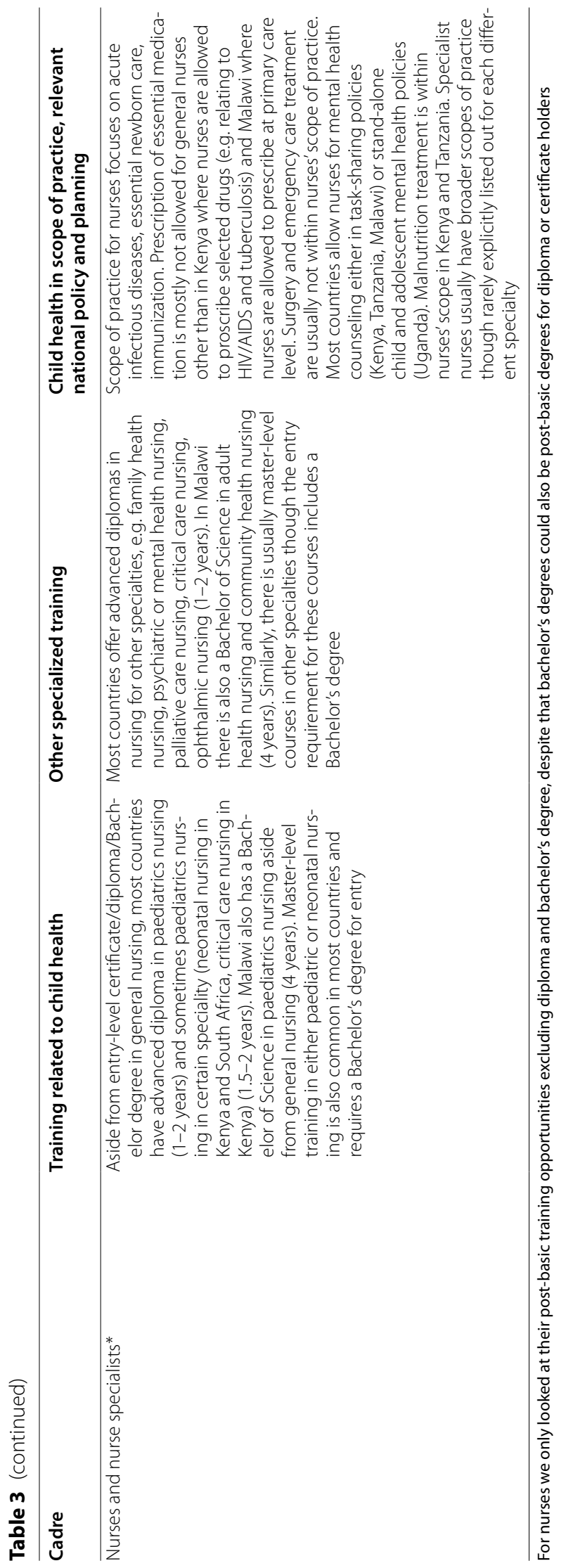


other relevant specialties (most commonly family medicine, anaesthesia, ophthalmology, ear nose and throat [ENT]), however this training is not specific to the paediatric age group and numbers of these specialist non-physician clinicians are much smaller than generalists.

Nurses too receive some training in child health as part of entry-level training courses and most countries offer advanced diplomas in neonatal or paediatric and child health nursing, while some also have Master's-level training which requires a Bachelor's degree for entry. This arrangement also applies to other relevant specialties that are not specific to paediatrics and child health (e.g. mental health/psychiatric, family medicine, critical care nursing). The scope of practice for nurses in general and often for those with advanced training is more restricted than for non-physician clinicians as in most countries such nurses are usually not authorized to prescribe. However, in primary care settings because of de facto/ informal task-sharing nurses may prescribe and in some countries nurses are legally allowed to prescribe selected drugs for acute and chronic illness mostly related to HIV/ AIDS and tuberculosis (Kenya) or at primary care level (Malawi). In some countries, malnutrition treatment and/or mental health counselling is within nurses' scope of practice while in Tanzania for example, nurses are not (officially) allowed to treat severe malnutrition at health centre level.

\section{Scoping review on task-sharing and paediatric and child health service delivery}

Table 4 shows the results of the scoping review on research evidence for task-sharing and paediatric and child health service delivery. A total of 83 papers were included for data charting, and $84 \%$ of the papers were published before 2010. The included studies covered 24 countries, 20 of which were African, most commonly Malawi $(n=14)$, Kenya $(n=12)$, Uganda $(n=12)$, South Africa $(n=8)$ and Tanzania $(n=6)$. Forty-nine studies assessed task-sharing as a new intervention, and 34 studies reported task-sharing as a norm, i.e. mentioned that services were routinely delivered by non-physicians but the study aim was not assessing task-sharing. Sixty-five studies used quantitative approaches (cross-sectional $(n=25)$, before-after $(n=13)$, non-randomized trials $(n=9))$. Ten used qualitative approaches either interviews $(n=5)$, case study/review $(n=5)$, mostly investigating how task-sharing initiatives were implemented and health workers' perspectives. Another 8 studies used mixed-method approaches. For the outcomes of care that were being shared assessed $(n=73$ quantitative and mixed-method studies), 18 studies assessed the lower cadres' knowledge, 28 studies their skills, and 35 patient outcomes including mortality, length of hospital stay, follow-up and adherence rates and patient satisfaction. We now consider findings organized by the type and complexity of conditions.

\section{Acute infectious diseases and malnutrition}

Forty-four papers examined acute infectious diseases and malnutrition, mostly examining HIV/AIDS testing, antiretroviral therapy (ART), and neonatal disorders as addressed in $\mathrm{IM}(\mathrm{N}) \mathrm{CI}$ and Emergency Triage Assessment and Treatment (ETAT). As we are more concerned with other conditions we do not present their findings here, but detailed characteristics of these studies are presented in Additional File 1.

\section{Minor surgery}

Seven studies reported male circumcision for infants or adolescents performed by clinical officers, nurses and midwives in Kenya, Uganda and Zambia [21-27]. This is a highly specific "acute" service focusing on HIV/AIDS prevention that does not generally extend the professional role too far and only requires short training (e.g. 5 days didactic and hands-on training [22]) with limited need for ongoing supervision. Studies report a relatively low adverse event rate (from 0\% [27] to 4.9\% highest [21]) and high patient and/or maternal satisfaction rate [23, 24]. One study reported minor burn services (wound care) provided by nurses at primary care while major burns were referred to secondary hospitals [28].

\section{Other complex surgery}

Five studies reported on amputation for some complex fractures, clubfoot corrective surgery, other orthopaedic surgery, burn surgery, ENT surgery and ventriculo-peritoneal (VP) shunting [29-33]. Three of these examined orthopaedic surgery delivered by clinical officers in Malawi and they reported an acceptable mortality rate when performed unsupervised as compared with specialists [31] and high cost-effectiveness [32]. One nonrandomized trial in Malawi suggested that when working together in central hospitals different cases were shared between clinical officers and physicians: most burn surgery, foreign body removal cases and ventriculo-peritoneal (VP) shunt placement were performed by clinical officers whereas general surgery, urology and congenital cases were more often performed by physicians, both groups had similar mortality and complication rates [29]. Another study focusing on VP-shunting in Malawi suggested that clinical officers operating alone had a slighter higher mortality rate than with a surgeon present $(6.6 \%$ vs. $5.9 \%)$, but comparable infection and shunting revision rates [33]. 


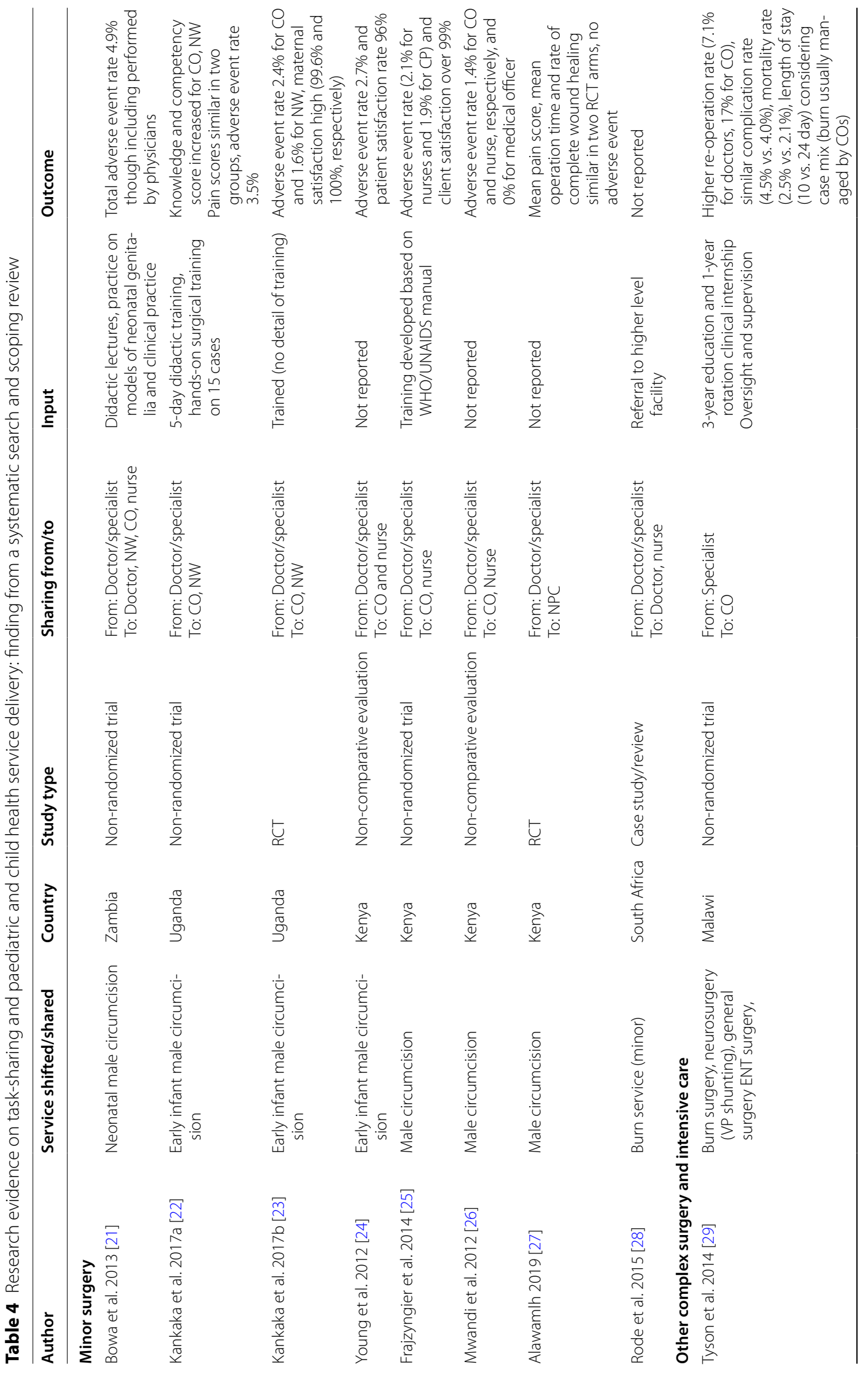




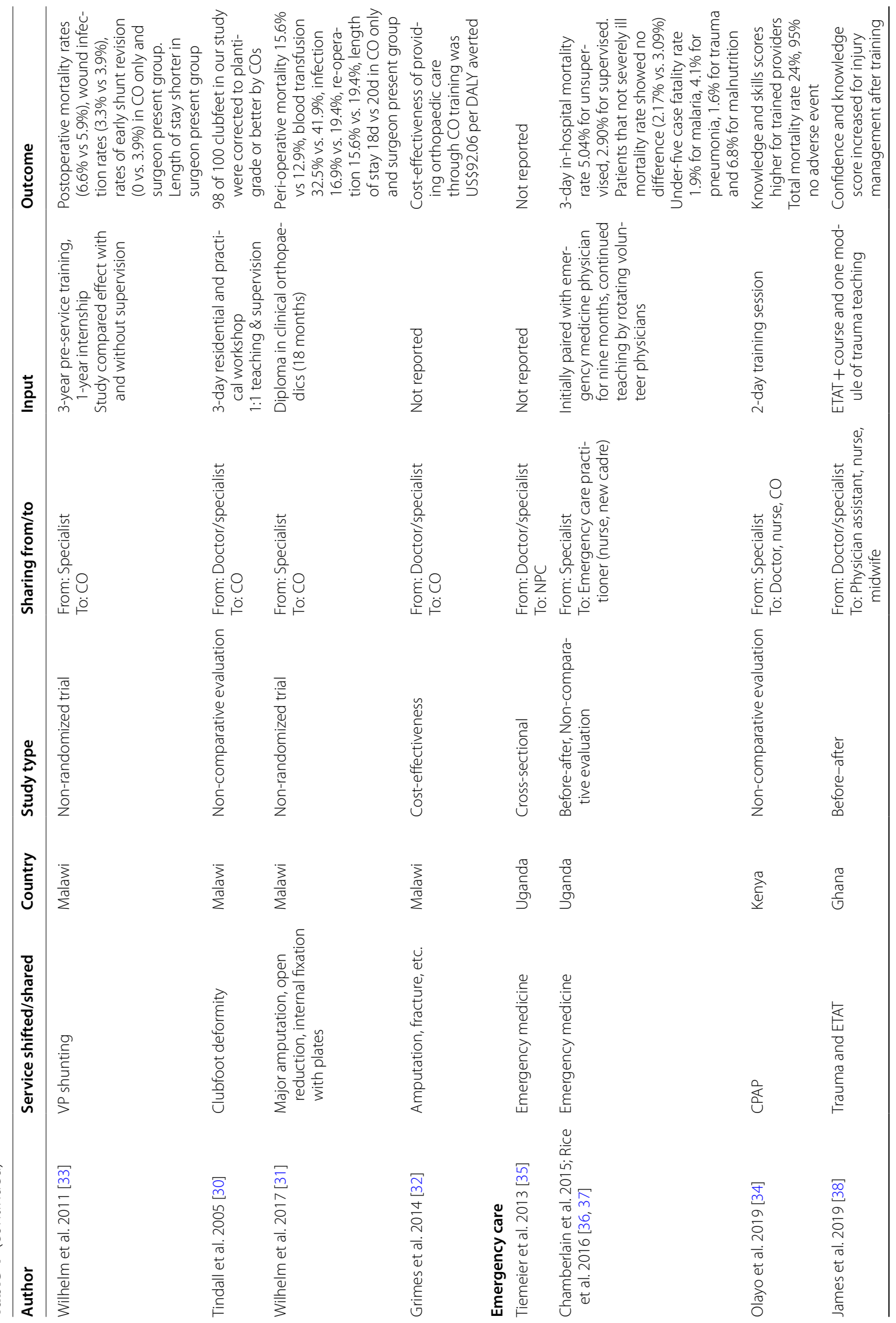




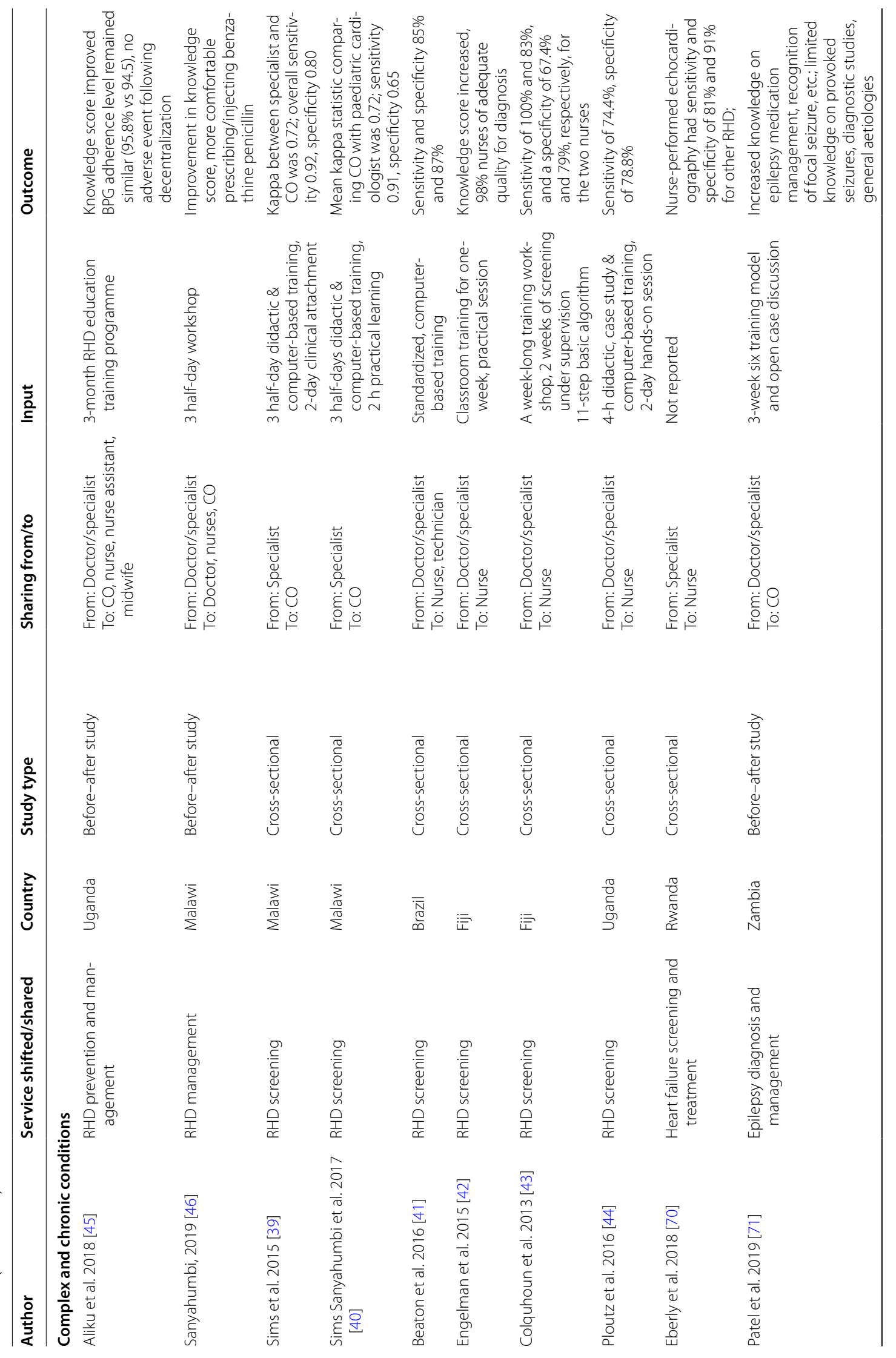




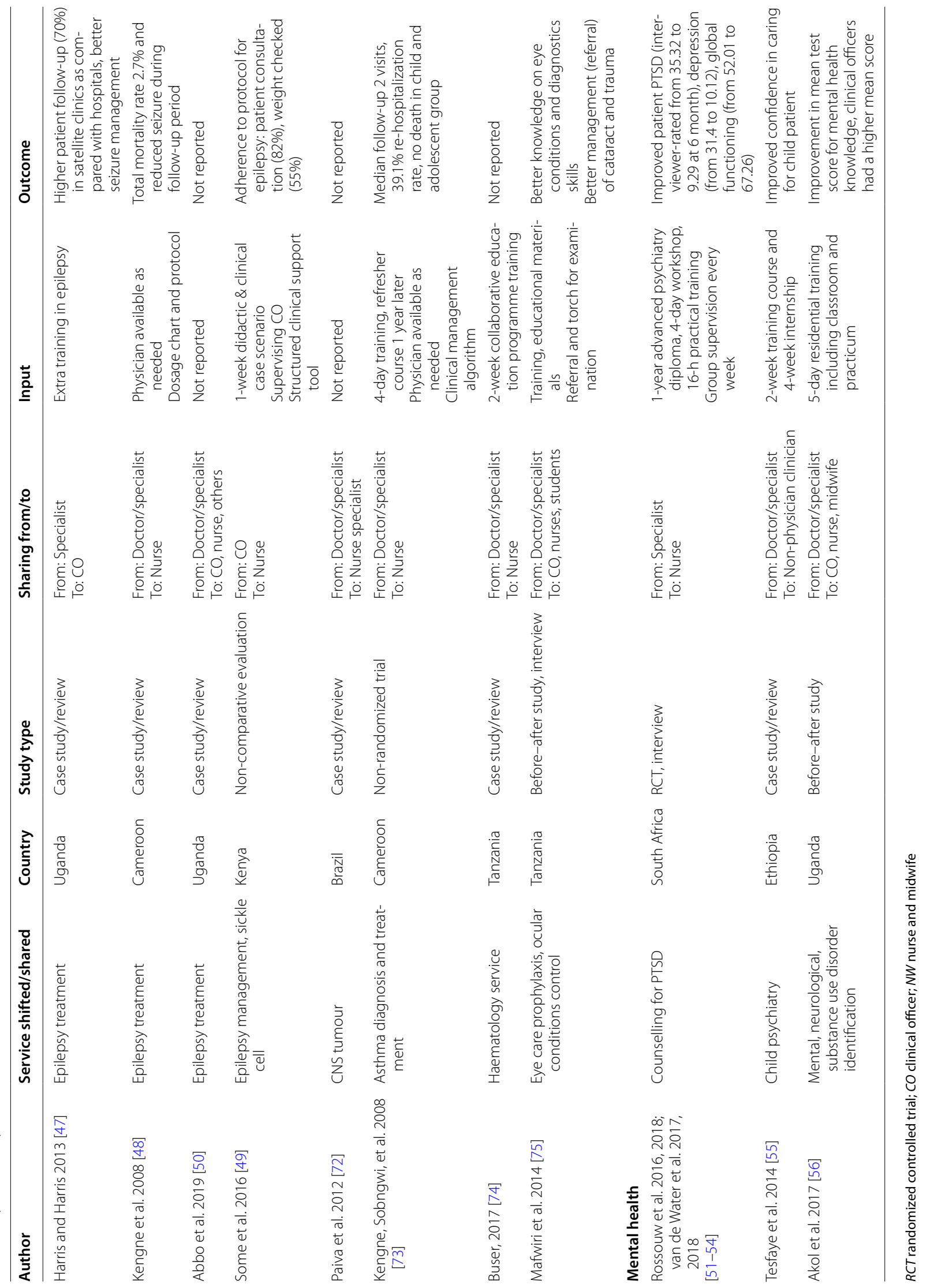




\section{Emergency care}

Five studies reported on "emergency care" in Kenya, Uganda and Ghana [34-38]. Task-sharing for emergency care usually includes additional in-service training to build on non-physician clinicians and nurses' pre-service training and requires initial pairing with specialists. In one Ugandan study, nurses were trained for 2 years as emergency care providers (a new cadre) with the goal that they could perform assessment, diagnosis and initiate treatment independently without physician supervision. However, the mortality rate nearly doubled when they practised unsupervised (5.04\%) vs. supervised (2.90\%), though for patients that were not severely ill there was no significant difference in mortality rate $(3.09 \%$ vs. $2.17 \%)$ $[36,37]$. One study also examined continuous positive airway pressure for neonatal and paediatric patients in Kenya [34] and reported an overall $24 \%$ mortality rate when performed by nurses and clinical officers. The other two studies reported only an increase in health worker knowledge of those taking on a new task [35, 38].

\section{Complex and chronic conditions}

Eighteen studies examined care for rheumatic heart diseases (RHD), epilepsy, sickle cell, asthma, eye care and tumours across seven African countries, Brazil and Fiji. Six studies examined the shifting of RHD screening to clinical officers, nurses, midwives and other cadres. With several days of additional training, these cadres achieved substantial agreement rates in RHD diagnosis using echocardiography as compared with specialists [39-44]. Two studies further reported on RHD treatment where health worker knowledge increased after training $[45,46]$. One reported good patient adherence rates for monthly prophylaxis after initial diagnosis and treatment at referral hospitals followed by task-shifting to health workers in local clinics [45]. Five studies investigated epilepsy. Diagnosis and management by clinical officers and nurses achieved better patient follow-up [47] and patient outcomes, e.g. mortality rate and seizure incidence [48] when care was decentralized rather than centralized in hospitals. In a study in Kenya, epilepsy treatment was shared from clinical officers to nurses who received additional training, dosage and management charts and continuous on-site supervision from clinical officers. Nurses showed moderate adherence to treatment protocols [49]. However, a qualitative study in Uganda showed that clinical officers and nurses in primary care had inadequate supervision and multidisciplinary rehabilitation team support when providing epilepsy care and they gradually lost their skills [50].

\section{Mental health}

Of six studies four were from one set of work in South Africa. These included randomized controlled trials of two different post-traumatic stress disorder (PTSD) treatments delivered by nurses for adolescents with subclinical PTSD in schools accompanied by qualitative work [51-54]. After initial diagnosis by a psychiatric nurse and/or a clinical psychologist, patients received treatment from nurses who were completing a 1-year advanced psychiatry diploma. Nurses also received group supervision every week from one clinical psychologist. Task-shifting in this study achieved satisfactory health outcomes (improved patient's PTSD score, depression and global functioning $[51,52])$ and was well-accepted by patients and nurses despite the latter initially resisting supervision $[53,54]$. Two other studies in Ethiopia [55] and Uganda [56], respectively, reported that health worker knowledge and skills improved after training for child and adolescent mental health.

\section{Discussion}

In this review, we explore for paediatric and child health services in LMICs likely areas of considerable service need. We focus on current approaches to training nonphysicians and nurses to support such care in five African countries and summarize existing findings from research on task-sharing for provision of complex and chronic paediatric and child health conditions. We discuss below the implications, potential opportunities and research gaps in work on task-sharing and paediatric and child health service delivery.

\section{Task-sharing for paediatric surgery, emergency and intensive care}

We found some training opportunities but rather limited policy opportunities for surgery, emergency and intensive care task-sharing. Non-physician clinicians could receive post-basic training in surgery, anaesthesia and emergency medicine. While most previous research evidence on task-sharing to non-physician clinicians or nurses focuses on adult and obstetrics services [57], research evidence on task-sharing for paediatric surgery has emerged over the past decade on circumcision, burn surgery, orthopaedics and VP shunts. Surgery for more complex cases (e.g. congenital defects) seems restricted to the few trained physicians despite a high disease burden. Similarly, while there are advanced courses on critical care nursing and reasonably well-established short-courses for emergencies, e.g. ETAT/ETAT + and helping babies breathe (HBB), these short courses do not aim to formally establish new professional roles or expand scopes of independent practice. In the few studies that are done on sharing complex surgery or emergency care the mortality rate of patients managed by unsupervised clinical officers and nurses may be higher compared with patients 
managed by physicians or supervised clinical officers/ nurses. Given the general deficits in the medical workforce especially in paediatric surgery and emergency care specialists $[6,58]$, it would seem worth exploring a more deliberate effort to develop specific paediatric task-sharing roles at hospital-level as has been practised for adults in Tanzania's assistant medical officers [59].

\section{Task-sharing for paediatric chronic conditions}

Task-sharing for these chronic conditions is likely to occur frequently in primary care to non-physician clinicians and nurses due to the shortage of physicians at this level [6]. Nonetheless, this is not clearly reflected in their training curricula and scopes of practices. Despite some examples of advanced paediatrics and family medicine training that covered most paediatrics subspecialties, the production of such professions is relatively small. For example, in 2018 there were only 255 clinical officers and 119 nurses with higher diplomas or master-level paediatric qualifications in Kenya despite some of these courses being introduced in the late 1970s [7, 60, 61].

Research evidence on task-sharing for chronic conditions is limited. Studies focus on mental health, RHD and epilepsy. Most were reasonably small in scale and examined either focused initial diagnosis (echocardiography for RHD diagnosis), or follow-up treatment in lower-level health facilities provided by clinical officers or nurses alone. The implementation experiences reported for mental health and epilepsy treatment suggest successful task-sharing requires sustained training and supervision, uninterrupted supplies of medications and sometimes support from specialized teams to meet complex medical and rehabilitation needs $[50,53]$. The challenges posed are similar to those for other non-communicable diseases and with the potential need for regular, scheduled followup countries need to consider how best to deliver this together with effective linkages between system levels.

\section{Implications and future considerations}

Countries with very few specialists in paediatrics or family medicine and that rely on these cadres to extend access to paediatric and child health care for more complex and chronic conditions might take decades to achieve this given the challenges of training capacity, duration and cost. Task-sharing to cadres with shorter training could be one solution to this human resources gap. However, several issues need to be highlighted. Providing such paediatric and child health services requires a system-approach with integrated models of care spanning healthcare organizations, communities, patients, and sometimes other stakeholders [62]. For example, long-term disability requires sustained interactions with the medical and rehabilitative services [4, 50, 63]. Careful, strategic thinking on the mix of cadres, their roles, regulation, financing and training and supervision and management of teams and services are needed [64-66]. To inform this much more might be learned from better evaluation of existing experience. Governments, regulatory councils and training institutions also need to enable changes in education, legislation, policy and financing well in advance of future expansion of service scope and scale as producing the desired mix of professions and skills may take years or even decades $[64,65]$.

Task-sharing strategies should also be mindful of professional identities and hierarchy [66, 67]. If further sharing of what are traditionally medical doctors and specialists' professional responsibilities with other cadres is being considered, policy-makers need to win doctors' endorsement and support to ensure effective task-sharing and the supportive supervision and team work that is needed for quality care. The planning needs to be context-specific, based on countries' existing structures, available resources, previous experiences of task-sharing and future planning for universal health coverage. There are multiple specific examples of more specialist roles for non-physician clinicians and nurses with post-basic training in paediatrics and child health. However, graduates of such programmes are relatively few and it is not clear that their development is part of broader strategic and holistic thinking of how paediatrics and child health care services might be delivered at scale by teams possibly comprising multiple professions. For example, legal restrictions on nurses' or non-physicians' prescribing even after specialist training may undermine efforts to expand coverage. To this end, better research is needed on the outcomes, quality of care and costs associated with task-sharing if it is to be a means of improving coverage and quality of care rather than associated with the provision of "secondrate" services $[68,69]$.

\section{Limitations}

Our study is not without limitations. Due to data and resource availability, we present secondary data on disease burden for 2019 instead of predicting the DALYs for the future. For the training opportunities and scope of practice review, we only examined five East and Southern Anglophone African countries. Paediatrician density is lowest in sub-Saharan Africa [6] and non-physician clinicians are more common in this region as evidenced by the fact that most identified research was from these countries. For the scoping review, we are only able to search and synthesize evidence reported in the research 
literature, in some circumstances task-sharing may already happen and become the norm, and therefore may not be reported in research papers. We also focused exclusively on task-sharing to professionals in the health sectors although it is well-known that other carers play a huge role in service delivery for chronic conditions.

\section{Conclusion}

The child health redesign agenda provides an ambitious outlook for children and adolescents in the SDG era, however addressing the human resources gap is a key challenge to further expand service provision. Our review summarized the current practices and emerging opportunities for task-sharing to support paediatric and child health service delivery in LMICs. While training opportunities for expanded services exist they produce relatively small numbers and non-physician clinicians' and nurses' training opportunities and scopes of practice are rather restricted. Aside from the historically shifted care of acute infectious diseases and malnutrition, there is limited research evidence on outcomes and quality of care for other forms of task-sharing. Service delivery arrangements for other priority conditions (congenital anomalies, major injuries, other chronic conditions, e.g. cancers, haemoglobinopathies) should be the subject of future research. To achieve coverage at scale countries may need to transform their paediatric and child health workforce including possible new roles for nurses, nonphysician clinicians and other allied health workers to support safe, accessible and high-quality care.

\section{Abbreviations}

ART: Antiretroviral therapy; DALYs: Disability-adjusted life-years; ETAT: Emergency Triage Assessment and Treatment; IMCl: Integrated Management of Childhood Illness; PTSD: Post-traumatic stress disorder; LMICs: Low- and middle-income countries; RHD: Rheumatic heart diseases; VP: Ventriculoperitoneal; WHO: World Health Organization.

\section{Supplementary Information}

The online version contains supplementary material available at https://doi. org/10.1186/s12960-021-00637-5.

Additional file 1: Scoping review appendix.

Additional file 2: Training opportunities and scope of practices related to child health for mid-level health workers in Kenya, Uganda, Tanzania, Malawi and South Africa.

\section{Acknowledgements}

We thank Eli Harriss, the Knowledge Centre Manager at the Bodleian Health Care Libraries, University of Oxford, for her support in literature search. We also thank Scott Smalley, Academic Head Division of Clinical Associates, University of the Witwatersrand South Africa, for his comment on training opportunities and scopes of practice for clinical associates in South Africa.

\section{Authors' contributions}

$\mathrm{YZ}$ and ME conceived of the analysis. $\mathrm{YZ}$ and $\mathrm{CH}$ contributed to study selection, data charting and collation for the scoping review. $Y Z$ wrote the first draft of the manuscript. ME, CH, RT, DG and NS provided critical feedback on the first draft of the manuscript. All authors read and approved the final manuscript.

\section{Funding}

$Y Z$ is supported by the University of Oxford Clarendon Fund Scholarship. ME is supported by a Wellcome Trust Senior Research Fellowship (Grant No. \#207522).

\section{Availability of data and materials}

All data relevant to the study are included in the article or uploaded as additional files.

\section{Declarations}

Ethics approval and consent to participate

Not required.

\section{Consent for publication}

Not required.

\section{Competing interests}

The authors declare no competing interests.

\section{Author details}

${ }^{1}$ Oxford Centre for Global Health Research, Nuffield Department of Medicine, University of Oxford, S Parks Rd, Oxford OX1 3SY, UK. ${ }^{2}$ Department of Health Policy Planning and Management, Makerere University School of Public Health, Kampala, Uganda. ${ }^{3}$ Department of Public Health, Lira University, Lira, Uganda. ${ }^{4}$ Department of Development Studies, School of Public Health and Social Sciences, Muhimbili University of Health and Allied Sciences, Dar es Salaam, Tanzania. ${ }^{5}$ KEMRI-Wellcome Trust Research Programme, Nairobi, Kenya. ${ }^{6}$ MARCH Centre, London School of Hygiene and Tropical Medicine, London, UK.

Received: 21 May 2021 Accepted: 23 July 2021

Published online: 04 August 2021

\section{References}

1. Lawn JE. The child survival revolution: what next? Lancet. 2014;384:931-3.

2. Claeson M, Waldman RJ. The evolution of child health programmes in developing countries: from targeting diseases to targeting people. Bull World Health Organ. 2000;78:1234-45.

3. Requejo J, Strong K. Redesigning health programmes for all children and adolescents. BMJ. 2021;372:n533.

4. Cieza A, Kamenov K, Sanchez MG, Chatterji S, Balasegaram M, Lincetto O, et al. Disability in children and adolescents must be integrated into the global health agenda. BMJ. 2021;372:n9.

5. World Health Organization. Global Strategy on Human Resources for Health: Workforce 2030 [Internet]. 2016. http://www.who.int/hrh/resou rces/globstrathrh-2030/en/

6. Harper BD, Nganga W, Armstrong R, Forsyth KD, Ham HP, Keenan WJ, et al. Where are the paediatricians? An international survey to understand the global paediatric workforce. BMJ Paediatr Open. 2019;3:bmjpo-2018-000397.

7. English M, Strachan B, Esamai F, Ngwiri T, Warfa O, Mburugu P, et al. The paediatrician workforce and its role in addressing neonatal, child and adolescent healthcare in Kenya. Arch Dis Child. 2020;105:927-31.

8. WHO |Task-shifting: global recommendations and guidelines [Internet]. WHO. World Health Organization; [cited 2020 May 15]. https://www.who. int/workforcealliance/knowledge/resources/taskshifting_guidelines/en/

9. Anand TN, Joseph LM, Geetha AV, Prabhakaran D, Jeemon P. Task sharing with non-physician health-care workers for management of blood pressure in low-income and middle-income countries: a systematic review and meta-analysis. Lancet Glob Health. 2019;7:e761-71. 
10. Mullan F, Frehywot S. Non-physician clinicians in 47 sub-Saharan African countries. Lancet. 2007;370:2158-63.

11. Huicho L, Scherpbier RW, Nkowane AM, Victora CG. How much does quality of child care vary between health workers with differing durations of training? An observational multicountry study. Lancet. 2008;372:910-6.

12. Joshi R, Alim M, Kengne AP, Jan S, Maulik PK, Peiris D, et al. Task-shifting for non-communicable disease management in low and middle income countries - a systematic review. PLoS ONE. 2014;9:e103754.

13. Javadi D, Feldhaus I, Mancuso A, Ghaffar A. Applying systems thinking to task-shifting for mental health using lay providers: a review of the evidence. Glob Ment Health [Internet]. Cambridge University Press; 2017 [cited 2021 Feb 10];4. https://www.cambridge.org/core/journals/ global-mental-health/article/applying-systems-thinking-to-task-shiftingfor-mental-health-using-lay-providers-a-review-of-the-evidence/C1 A56 AD40142E62336517A2A10AA7946

14. Penazzato M, Davies M-A, Apollo T, Negussie E, Ford N. Task-shifting for the delivery of pediatric antiretroviral treatment: a systematic review. JAIDS J Acquir Immune Defic Syndr. 2014;65:414-22.

15. Dovlo D. Using mid-level cadres as substitutes for internationally mobile health professionals in Africa. A desk review. Hum Resour Health. 2004:2:7.

16. Tweheyo R, Reed C, Campbell S, Davies L, Daker-White G.'I have no love for such people, because they leave us to suffer': a qualitative study of health workers' responses and institutional adaptations to absenteeism in rural Uganda. BMJ Glob Health. 2019;4:e001376.

17. Vos T, Lim SS, Abbafati C, Abbas KM, Abbasi M, Abbasifard M, et al. Global burden of 369 diseases and injuries in 204 countries and territories, 1990-2019: a systematic analysis for the Global Burden of Disease Study 2019. Lancet. 2020;396:1204-22.

18. You D, Beise J, Lee S, Requejo J, Strong K. Demographic challenges and opportunities for child health programming in Africa and Asia. BMJ. 2021;372:n19

19. Arksey H, O'Malley L. Scoping studies: towards a methodological framework. Int J Soc Res Methodol Routledge. 2005;8:19-32.

20. LMIC Filters [Internet]. [cited 2021 Feb 9]. /Imic-filters

21. Bowa K, Li MS, Mugisa B, Waters E, Linyama DM, Chi BH, et al. A controlled trial of three methods for neonatal circumcision in Lusaka, Zambia. J Acquir Immune Defic Syndr. 1999;2013(62):e1-6.

22. Kankaka EN, Kigozi G, Kayiwa D, Kighoma N, Makumbi F, Murungi T, et al. Efficacy of knowledge and competence-based training of non-physicians in the provision of early infant male circumcision using the Mogen clamp in Rakai, Uganda. BJU Int. 2017;119:631-7.

23. Kankaka EN, Murungi T, Kigozi G, Makumbi F, Nabukalu D, Watya S, et al. Randomised trial of early infant circumcision performed by clinical officers and registered nurse midwives using the Mogen clamp in Rakai, Uganda. BJU Int. 2017;119:164-70

24. Young MR, Bailey RC, Odoyo-June E, Irwin TE, Obiero W, Ongonga DO, et al. Safety of over twelve hundred infant male circumcisions using the Mogen Clamp in Kenya. PLoS ONE. 2012;7:5.

25. Frajzyngier $V$, Odingo G, Barone M, Perchal P, Pavin M. Safety of adult medical male circumcision performed by non-physician clinicians in Kenya: a prospective cohort study. Glob Health Sci Pract. 2014;2:93-102.

26. Mwandi Z, Ochieng A, Grund J, Mwalili S, Kimanga D, Otieno G, et al. Service delivery trends in Kenya's voluntary medical male circumcision scale-up from 2008-2011. J Int Aids Soc. 2012;2012:136-7.

27. Al Hussein Alawamlh O, Kim SJ, Barone M, Awori Q, Oketch J, Otiende P, Nyangweso N, Maina M, Kiswi N, Goldstein M, Li PS. Pd08-11 use of topical anesthesia with the shangring male circumcision device: a randomized clinical trial in kenya. J Urol. 2019;201:e152-3.

28. Rode $H$, Rogers AD, Numanoglu A, Wallis $L$, Allgaier $R$, Laflamme $L$, et al. A review of primary and secondary burn services in the Western Cape, South Africa. S Afr Med J. 2015;105:852.

29. Tyson AF, Msiska N, Kiser M, Samuel JC, Mclean S, Varela C, et al. Delivery of operative pediatric surgical care by physicians and nonphysician clinicians in Malawi. Int J Surg Lond Engl. 2014;12:509-15.

30. Tindall AJ, Steinlechner CWB, Lavy CBD, Mannion S, Mkandawire N. Results of manipulation of idiopathic clubfoot deformity in Malawi by orthopaedic clinical officers using the Ponseti method: a realistic alternative for the developing world? J Pediatr Orthop. 2005;25:627-9.

31. Wilhelm TJ, Dzimbiri K, Sembereka V, Gumeni M, Bach O, Mothes H. Task-shifting of orthopaedic surgery to non-physician clinicians in Malawi: effective and safe? Trop Doct. 2017:47:294-9.
32. Grimes CE, Mkandawire NC, Billingsley ML, Ngulube C, Cobey JC. The cost-effectiveness of orthopaedic clinical officers in Malawi. Trop Doct. 2014:44:128-34.

33. Wilhelm TJ, Thawe IK, Mwatibu B, Mothes H, Post S. Efficacy of major general surgery performed by non-physician clinicians at a central hospital in Malawi. Trop Doct. 2011:41:71-5.

34. Olayo B, Kirigia CK, Oliwa JN, Agai ON, Morris M, Benckert M, et al. Effective training-of-trainers model for the introduction of continuous positive airway pressure for neonatal and paediatric patients in Kenya. Paediatr Int Child Health. 2019;39:193-200.

35. Tiemeier K, Bisanzo M, Dreifuss B, Ward KC. The effect of geography and demography on outcomes of emergency department patients in rural Uganda. Ann Emerg Med. 2013;62:S99.

36. Chamberlain S, Stolz U, Dreifuss B, Nelson SW, Hammerstedt $\mathrm{H}$, Andinda J, et al. Mortality related to acute illness and injury in rural Uganda: task-shifting to improve outcomes. PLoS ONE. 2015;10:e0122559.

37. Rice B, Periyanayagam U, Chamberlain S, Dreifuss B, Hammerstedt $H$, Nelson S, et al. Mortality in children under five receiving nonphysician clinician emergency care in Uganda. Pediatrics. 2016;137:e20153201.

38. James DR, Barling J, Ross O, Daniel AA, Crocker C, Jarvis E, et al. G293 (P) Towards emergency triage assessment and treatment (ETAT)++: introducing basic paediatric trauma management skills in rural Ghana. Arch Dis Child. 2019;104:A120.

39. Sims AE, Sable CA, Hosseinipour M, Karlsten M, Kazembe PN, Minard CG, et al. Clinical-officer led echocardiographic screening is sensitive for diagnosing rheumatic heart disease in Malawi, Africa. Circulation. 2015;132:A18009-A18009.

40. Sims Sanyahumbi A, Sable CA, Karlsten M, Hosseinipour MC, Kazembe PN, Minard CG, et al. Task-shifting to clinical officer-led echocardiography screening for detecting rheumatic heart disease in Malawi, Africa. Cardiol Young. 2017;27:1133-9.

41. Beaton A, Nascimento B, Diamantino A, Perlman L, Tompsett A, Ribeiro A, et al. PS018 Task-shifting of handheld echocardiographic screening for rheumatic heart disease: longitudinal performance of non-experts in a school-based program. Glob Heart. 2016;11:e19.

42. Engelman D, Kado J, Remenyi B, Watson C, Rayasidamu S, Steer A, et al. Teaching focused echocardiography for rheumatic heart disease screening. Ann Pediatr Cardiol. 2015;8:118.

43. Colquhoun SM, Carapetis JR, Kado JH, Reeves BM, Remenyi B, May W, et al. Pilot study of nurse-led rheumatic heart disease echocardiography screening in Fiji - a novel approach in a resource-poor setting. Cardiol Young. 2013;23:546-52.

44. Ploutz M, Lu JC, Scheel J, Webb C, Ensing GJ, Aliku T, et al. Handheld echocardiographic screening for rheumatic heart disease by nonexperts. Heart. 2016;102:35-9.

45. Aliku TO, Adong C, Kamarembo J, Akech R, Odong F, Apiyo P. PO552 assessment of the impact of a training program on knowledge and clinical practices of health workers regarding rheumatic heart disease prevention in lower level health centers in gulu municipality, Uganda. Glob Heart. 2018;13:495.

46. Sanyahumbi A. Education: The prevention of acute rheumatic fever and rheumatic heart disease in Malawi. Malawi Med J. 2019;31:221-2.

47. Harris $\mathrm{C}$, Harris U. Combating barriers to epilepsy treatment in Western Uganda. Trop Med Int Health. 2013;18:83-83.

48. Kengne AP, Fezeu LL, Awah PK, Sobngwi E, Dongmo S, Mbanya JC. Nurseled care for epilepsy at primary level in a rural health district in Cameroon. Epilepsia. 2008:49:1639-42.

49. Some D, Edwards JK, Reid T, Van den Bergh R, Kosgei RJ, Wilkinson E, et al. Task-shifting the management of non-communicable diseases to nurses in Kibera, Kenya: does it work? PLoS ONE. 2016;1 1:e0145634.

50. Abbo C, Mwaka AD, Opar BT, Idro R. Qualitative evaluation of the outcomes of care and treatment for children and adolescents with nodding syndrome and other epilepsies in Uganda. Infect Dis Poverty. 2019:8:30.

51. Rossouw J, Yadin E, Alexander D, Mbanga I, Jacobs T, Seedat S. A pilot and feasibility randomised controlled study of Prolonged Exposure Treatment and supportive counselling for post-traumatic stress disorder in adolescents: a third world, task-shifting, community-based sample. Trials. 2016;17:548

52. Rossouw J, Yadin E, Alexander D, Seedat S. Prolonged exposure therapy and supportive counselling for post-traumatic stress disorder in 
adolescents: task-shifting randomised controlled trial. Br J Psychiatry J Ment Sci. 2018;213:587-94.

53. van de Water T, Rossouw J, Yadin E, Seedat S. Impediments and catalysts to task-shifting psychotherapeutic interventions for adolescents with PTSD: perspectives of multi-stakeholders. Child Adolesc Psychiatry Ment Health. 2017;11:48.

54. van de Water T, Rossouw J, Yadin E, Seedat S. Adolescent and nurse perspectives of psychotherapeutic interventions for PTSD delivered through task-shifting in a low resource setting. PLoS ONE. 2018;13:e0199816.

55. Tesfaye M, Abera M, Gruber-Frank C, Frank R. The development of a model of training in child psychiatry for non-physician clinicians in Ethiopia. Child Adolesc Psychiatry Ment Health. 2014;8:6.

56. Akol A, Nalugya J, Nshemereirwe S, Babirye JN, Engebretsen IMS. Does child and adolescent mental health in-service training result in equivalent knowledge gain among cadres of non-specialist health workers in Uganda? A pre-test post-test study. Int J Ment Health Syst. 2017;11:50.

57. Chu K, Rosseel P, Gielis P, Ford N. Surgical task-shifting in Sub-Saharan Africa. PLoS Med. 2009;6:e1000078.

58. Obermeyer Z, Abujaber S, Makar M, Stoll S, Kayden SR, Wallis LA, et al. Emergency care in 59 low-and middle-income countries: a systematic review. Bull World Health Organ. 2015;93:577-86.

59. Rick TJ, Moshi DD. The Tanzanian assistant medical officer. J Am Acad PAs. 2018:31:43-7

60. Couper I, Ray S, Blaauw D, Ngwena G, Muchiri L, Oyungu E, et al. Curriculum and training needs of mid-level health workers in Africa: a situational review from Kenya, Nigeria, South Africa and Uganda. BMC Health Serv Res. 2018;18:553.

61. Kenya Ministry of Health. Kenya Harmonised Health Facility Assessment Survey. 2018

62. Graham H, Tokhi M, Duke T. Scoping review: strategies of providing care for children with chronic health conditions in low- and middle-income countries. Trop Med Int Health TM IH. 2016;21:1366-88.

63. Simon JL, Daelmans B, Boschi-Pinto C, Aboubaker S, Were W. Child health guidelines in the era of sustainable development goals. BMJ. 2018;362:bmj.k3151.

64. Bac M, Hamm JMA, van Bodegraven PC, Pater B, Louw JM. A new health care profession in rural district hospitals: a case study of the introduction of clinical associates in Shongwe hospital. S Afr Fam Pract. 2017;59:14-7.
65. Lehmann U, Van Damme W, Barten F, Sanders D. Task-shifting: the answer to the human resources crisis in Africa? Hum Resour Health. 2009;7:49.

66. Mijovic H, McKnight J, English M. What does the literature tell us about health workers' experiences of task-shifting projects in sub-Saharan Africa? A systematic, qualitative review. J Clin Nurs. 2016;25:2083-100.

67. Dambisya YM, Matinhure S. Policy and programmatic implications of taskshifting in Uganda: a case study. BMC Health Serv Res. 2012;12:61.

68. World Health Organization. Task-shifting to tackle health worker shortages. Geneva:WHO; 2007

69. Fulton BD, Scheffler RM, Sparkes SP, Auh EY, Vujicic M, Soucat A. Health workforce skill mix and task-shifting in low income countries: a review of recent evidence. Hum Resour Health. 2011;9:1.

70. Eberly L, Rusingiza E, Park P, Ngoga G, Dusabeyezu S, Mutabazi F, et al. Heart failure as an entry point for severe cardiovascular disease in sub-saharan Africa: 10-year experience with nurse-led diagnosis and treatment at district hospitals in rural Rwanda. J Am Coll Cardiol. 2018;71:A656-A656.

71. Patel AA, Wibecan L, Tembo O, Kalyelye P, Mathews M, Ciccone O. Improving paediatric epilepsy management at the first level of care: a pilot education intervention for clinical officers in Zambia. BMJ Open. 2019;9:e029322.

72. Paiva P, Cappellano A, Dias C, Silva N. Project clinical nurse specialist in neuro-oncology: experience report. Neuro Oncol. 2012;14:123-123.

73. Kengne AP, Sobngwi E, Fezeu LL, Awah PK, Dongmo S, Mbanya JC, et al. Nurse-led care for asthma at primary level in rural Sub-Saharan Africa: the experience of bafut in Cameroon. J Asthma. 2008;45:437-43.

74. Buser JM. The need for hematology nurse education in low- and middleincome countries: a community case study in Tanzania. Front Public Health. 2017;5:65.

75. Mafwiri MM, Kisenge R, Gilbert CE. A pilot study to evaluate incorporating eye care for children into reproductive and child health services in Dares-Salaam, Tanzania: a historical comparison study. BMC Nurs. 2014;13:15.

\section{Publisher's Note}

Springer Nature remains neutral with regard to jurisdictional claims in published maps and institutional affiliations.
Ready to submit your research? Choose BMC and benefit from:

- fast, convenient online submission

- thorough peer review by experienced researchers in your field

- rapid publication on acceptance

- support for research data, including large and complex data types

- gold Open Access which fosters wider collaboration and increased citations

- maximum visibility for your research: over 100M website views per year

At BMC, research is always in progress.

Learn more biomedcentral.com/submissions 